\title{
A Study on Child Sexual Abuse in Galle - A Descriptive Retrospective Study
}

\author{
R. H. A. I. Rathnaweera1, K. R. Munasingha², D. Amarasingha'
}

\begin{abstract}
Introduction: The estimation of any form of deviance in the general population is a very difficult task. It is impossible to assess the extent of sexual offending, either in general or with children as targets. Therefore an in depth study should be conducted to explore the real situation.
\end{abstract}

Objective: Routine data pertaining to victims of alleged child sexual abuse (CSA) were analyzed to explain the nature and characteristics of people, place, time, and patterns of CSA with special reference to injuries.

Materials and Methods: All the CSA cases referred to the JMO's office, Teaching hospital, Karapitiya form $1^{\text {st }}$ April 2013 to $31^{\text {st }}$ March 2015 were retrospectively analyzed.

Results: During the study period, 296 victims were referred, 281 were female. 210 (70\%) were between 11 to 15 years and majority (88\%) were belonging to lower socio-economic classes. 173 (59\%) female victims "consented" for the alleged act whereas none of the male victims did. Majority of female sexual abuse offenders were aged below 25 years whereas for male, aged above 35 years ( $>00.05)$. Ano-genital injuries in female victims at presentation is more frequent compared to male victims $(\mathrm{p}>0.05)$. 116(41\%) female victims had hymenal tears, out of that, only 18 are fresh tears. 14 victims complained of alleged anal abuse but only 2 had identifiable injuries. Extra genital injuries were present only in female victims $(1.5 \%)$. Only $57(20 \%)$ presented with original clothing \& only $20(6.7 \%)$ presented within first 24 hours. Spermatozoa were identified only in 6 referred cases to government analyst.

Conclusions: Children below 16 years of age from lower socio-economic group were more prone to sexual abuse. The given "consent" and delayed presentation could be a reason for lack of injuries in both groups. Young males have shown preference for female victims whereas older males have shown preference for younger boys. Low positive spermatozoa identification could be due to delayed presentation \& baths and changing clothes prior to referral. Steps needed to be taken to speed up the referral of victims with their original clothing in order to prevent loss of valuable evidence.

Key words: child sexual abuse, Galle, ano-genital injuries, hymenal tears. 


\section{INTRODUCTION}

The term "child" is used to refer to anyone under the age of 18 years. Although child sexual abuse (CSA) is recognized as a serious violation of human well-being and of the law, no community has yet developed mechanisms that ensure that none of their youth will be sexually abused. CSA is, sadly, an international problem of great magnitude that can affect children of all ages, sexes, races, ethnicities, and socioeconomic classes.

Until recently, there was much disagreement as to what should be included in the definition of CSA (1). In some definitions, only contact abuse was included, such as penetration, fondling, kissing, and touching (2). Noncontact sexual abuse, such as exhibitionism and voyeurism, were not always considered abusive. Nowadays, the field is evolving towards a more inclusive understanding of CSA that is broadly defined as any sexual activity perpetrated against a minor by threat, force, intimidation, or manipulation. The array of sexual activities thus includes fondling, inviting a child to touch or be touched sexually, intercourse, rape, incest, sodomy, exhibitionism, involving a child in prostitution or pornography, or online child luring by cyber predators $(3,4)$.
Only recently, in our country, the sexual abuse of children has come to be seen as a major social problem and a main cause of suffering of many people. A study conducted in the early 1990s among 899 pre-university and undergraduate students in Sri Lanka revealed that $18 \%$ of boys and $4.5 \%$ of girls had been sexually abused in childhood4. Some believe that, for the first time in history, we are beginning to face the true prevalence and significance of child sexual abuse. Others worry that many people have become obsessed with child sexual abuse and deny any personal responsibility for their problems while "blaming" them on abuse and bad parenting.

\section{OBJECTIVE}

Objective in this study was to explain the nature and characteristics of people, place, time, and patterns of child sexual abuse with special reference to injuries, to identify the consequences of child sexual abuse and to identify factors important for policy making for solving the problem of child sexual abuse.

\section{MATERIALS AND METHODS}

All the child sexual abuse cases referred to the JMO's office, teaching hospital, Karapitiya, Galle, form 1st of April 2013 to 31 st of March 2015 were retrospectively 
analyzed. As the primary source, medicolegal examination forms (MLEF) of all the child sexual abuse victims were used and as secondary sources, bed head tickets and other relevant medical reports were used. The medico legal records of 296child sexual abuse cases were evaluated and routine data were analyzed by using Microsoft Excel and SPSS software.

The different types of assault were defined as penetration (with penis, hand, or foreign object) vaginal, oral, anal or a combination of the three, alternatively others when no penetration was involved but other kinds of touching or kissing had occurred (involving genitals or body parts). Violence was defined as hitting, kicking, holding, attempts of strangulation, or by other means. Genital injuries were defined when swelling (oedematous tissues), redness (erythemous skin), ecchymoses (skin or mucous membrane discolorations, known as bruising), tears (breaks in tissue including fissures, cracks, cuts and lacerations), and several (more than one of the above mentioned injuries) were observed. The different genital injury locations are defined as vulva, introitus, labia minora, posterior fourchette, hymen, and vagina.

\section{RESULTS}

During the study period, 296 victims were referred for medico-legal examination with an alleged history of sexual abuse and out of that $281(94 \%)$ were female. The age of the victims ranged from 4 years to 18 years (Table 1). 210 (70\%) victims were between 11 to 15 years of age. Out of the female victims $231(80 \%)$ were found to have attained menarche at the time of sexual abuse.

Majority $(40 \%)$ of the victims were referred after 72 hours of the alleged incident (Table 2).

The alleged incident had taken place at the victims' house in 128 (43\%) cases (Table $3)$.

Majority of the victims were abused by a single assailant 286 (98\%) (Table 4) and the assailant was known in 279 (95\%) cases. The alleged assailant (Table 5) was a boyfriend in majority of female sexual abuse cases (54\%) where as in male sexual abuse cases it was a known neighbor $(2.7 \%)$. Six female victims were found to be living together with their boyfriends at the time of police intervention.

Assailants were aged from 17 to 64 years (Table 6). There was a statistically significant difference ( $\mathrm{p}$ value $<0.05$ ) in relation to the age of the offenders. Majority of female sexual abuse offenders were aged below 25 years $(80 \%)$ whereas 
male sexual abuse offenders were aged above 35 years $(3.7 \%)$.

The commonest type of alleged abuse in female victims was vaginal intercourse where as in males it was intercrural intercourse (Table 7). 173(59\%) female victims and 04(1.3\%) male victims found to have given "consent" for the alleged act (table 08).

After the alleged abuse, 225 female victims and 12 male victims found to have changed their clothes prior to examination by a doctor (Table 9).

21 female victims and 03 male victims had a past history of alleged sexual abuse. 42 female victims found to have had "consented" sexual intercourse during the past. Majority $(88 \%)$ of the victims were belonging to lower socio-economic classes where as $10 \%$ to middle classes and only $2 \%$ to higher classes. $256(86 \%)$ had not studied beyond grade 10 .

Majority of victims found to be living with their parents $(37 \%)$ in their own houses $(73 \%)$.

Annular hymen 138 (49\%) was the commonest type of hymen found among the femal victims followed by fimbriated $87(31 \%)$ and cresentic 46(16\%) (Table $10)$.

There was a statistically significant difference in relation to presence of anogenital injuries $(\mathrm{p}$ value $<0.05$ ). Female victims were found to have presented with ano-genital injuries more frequently (67\%) in comparison to male victims $(6 \%)$ (Table 11). Out of the female victims only 18 (6\%) had fresh tears (Table 12).

6 o clock was the commonest place for hymenal tear followed by 9 o clock and 3 o clock (Table 13).

Only the female victims found to have extra genital injuries and they were present only in $4(1.5 \%)$ cases. All the victims with extra genital injuries were abused by unknown offenders. Abrasion was the commonest type of injury found and the face was the commonest place injured followed by upper limbs and lower limbs.

Pregnancy test was performed on 38 female victims and it was positive on three. Swabs for spermatozoa were collected on 245 victims and it was positive only on 6 female victims. None of the male victims had positive results. All victims were referred for sexually transmitted infection screening and 18 female victims and one male victim had positive results. All victims were referred to psychiatrist and 37 female and 4 male victims found to have some form of mental health issues. 161 female victims were referred to obstetrician and out of that 3 were confirmed to be pregnant. Six victims were referred to radiologist for age assessment. 
RATHNAWEERA, R. H. A. I., MUNASINGHA, K. R., AMARASINGHA, D., A study on child sexual abuse in Galle - a descriptive retrospective study. Sri Lanka Anatomy Journal (SLAJ), 1(1): 34-43, 2017.

Table 1. Age of the victims

\begin{tabular}{lll} 
& Male & Female \\
\hline Age (years) & No: & No: \\
\hline $01-05$ & $01(0.3 \%)$ & $08(2.7 \%)$ \\
$06-10$ & $09(3.0 \%)$ & $27(9.1 \%)$ \\
$11-15$ & $05(1.6 \%)$ & $205(69 \%)$ \\
$16-18$ & 00 & $41(13 \%)$ \\
\hline
\end{tabular}

Table 2. Time gap

\begin{tabular}{ll}
\hline Time gap & No: \\
\hline$<06$ hours & $03(1 \%)$ \\
$06-24$ hours & $17(5.7 \%)$ \\
$24-48$ hours & $49(16 \%)$ \\
$48-72$ hours & $107(36 \%)$ \\
$>72$ hours & $120(40 \%)$ \\
\hline
\end{tabular}

Table 3. Place of the alleged incident

\begin{tabular}{lll} 
& Male & Female \\
\hline Place & No: & No: \\
\hline Victims home & $03(1 \%)$ & $125(42 \%)$ \\
Assailants home & $06(2 \%)$ & $39(13 \%)$ \\
Deserted place & $02(0.6 \%)$ & $18(5.7 \%)$ \\
Temple/mosque/church & $04(1.3 \%)$ & $02(0.6 \%)$ \\
Hotel/guest house & -- & $38(13 \%)$ \\
Friends home & --- & $10(03 \%)$ \\
Relatives home & --- & $29(10 \%)$ \\
Neighbors' home & --- & $30(8 \%)$ \\
School & -- & $02(0.6 \%)$ \\
Film hall & --- & $03(1 \%)$ \\
\hline
\end{tabular}

Table 4. No of assailants

\begin{tabular}{lll} 
& Male & Female \\
\hline No of assailants & No: & No: \\
\hline 01 & $11(3.7 \%)$ & $275(94 \%)$ \\
02 & $02(0.6 \%)$ & $04(1.3 \%)$ \\
$>02$ & $02(0.6 \%)$ & $02(0.6 \%)$ \\
\hline
\end{tabular}


RATHNAWEERA, R. H. A. I., MUNASINGHA, K. R., AMARASINGHA, D., A study on child sexual abuse in Galle - a descriptive retrospective study. Sri Lanka Anatomy Journal (SLAJ), 1(1): 34-43, 2017.

Table 5. Alleged assailant

\begin{tabular}{lll} 
& Male & Female \\
\hline Assailant & No: & No: \\
\hline Relative & $02(0.6 \%)$ & $14(4.8 \%)$ \\
Neighbor & $08(2.7 \%)$ & $28(9.6 \%)$ \\
Priest & $04(1.3 \%)$ & $02(0.6 \%)$ \\
Boyfriend & --- & $160(54 \%)$ \\
Teacher & --- & $02(0.6 \%)$ \\
Father & --- & $10(8 \%)$ \\
Any other & --- & $49(17 \%)$ \\
Unknown & $01(0.3 \%)$ & $16(5.4 \%)$ \\
\hline
\end{tabular}

Table 6. Age of the assailant

\begin{tabular}{lll} 
& Male & Female \\
\hline Age of the assailant & No: & No: \\
\hline$>15$ & 00 & 00 \\
$16-20$ & $01(0.3 \%)$ & $86(29 \%)$ \\
$21-25$ & $02(0.6 \%)$ & $148(51 \%)$ \\
$26-30$ & $01(0.3 \%)$ & $19(6.5 \%)$ \\
$31-35$ & 00 & $07(2.4 \%)$ \\
$36-40$ & $07(2.4 \%)$ & $08(2.7 \%)$ \\
$41-45$ & $03(1 \%)$ & $06(2 \%)$ \\
$46-50$ & $01(0.3 \%)$ & $04(1.3 \%)$ \\
$51-55$ & 00 & $02(0.6 \%)$ \\
$56-60$ & 00 & $01(0.3 \%)$ \\
\hline
\end{tabular}

Table 7. Type of abuse

\begin{tabular}{lll} 
& Male & Female \\
\hline Type of abuse & No: & No: \\
\hline Fondling & 06 & 87 \\
Intercrural intercourse & 11 & 37 \\
Anal intercourse & 04 & 07 \\
Kissing & -- & 178 \\
Oral intercourse & -- & 65 \\
Vaginal intercourse & -- & 197 \\
Exhibitionism & -- & 05 \\
Combination & 08 & 169 \\
\hline
\end{tabular}


RATHNAWEERA, R. H. A. I., MUNASINGHA, K. R., AMARASINGHA, D., A study on child sexual abuse in Galle - a descriptive retrospective study. Sri Lanka Anatomy Journal (SLAJ), 1(1): 34-43, 2017.

Table 8. In obtaining consent

\begin{tabular}{lll} 
& Male & Female \\
\hline In obtaining consent & No: & No: \\
\hline Use of threat & $14(4.8 \%)$ & $73(25 \%)$ \\
Hurt & $03(0.6 \%)$ & $06(2 \%)$ \\
Fear of death & -- & $24(8 \%)$ \\
Detention & -- & -- \\
Unsound mind & -- & $05(1.7 \%)$ \\
Intoxication & -- & $02(0.6 \%)$ \\
"Consented" & -- & $173(60 \%)$
\end{tabular}

Table 9. Following alleged abuse

\begin{tabular}{lll}
\hline & Male & Female \\
\hline Following abuse & No: & No: \\
\hline Change clothes & 09 & 225 \\
Wash / Bath & 12 & 191 \\
Urinate & 12 & 262 \\
Defecate & 07 & 178 \\
Brush teeth & 11 & 243 \\
Rinse mouth & 11 & 256 \\
Use of tampon or pads & -- & 14 \\
Vomit & -- & 02 \\
\hline
\end{tabular}

Table 10. Type of hymen

\begin{tabular}{ll}
\hline Type of hymen & No: \\
\hline Annular & $138(49 \%)$ \\
Fimbriated & $87(31 \%)$ \\
Crecentic & $46(16 \%)$ \\
Septate & $02(0.7 \%)$ \\
Attenuated & $08(3 \%)$ \\
\hline
\end{tabular}


RATHNAWEERA, R. H. A. I., MUNASINGHA, K. R., AMARASINGHA, D., A study on child sexual abuse in Galle - a descriptive retrospective study. Sri Lanka Anatomy Journal (SLAJ), 1(1): 34-43, 2017.

Table 11. Type of injury

\begin{tabular}{lll} 
& Male & Female \\
\hline Type of injury & No: & No: \\
\hline
\end{tabular}

Anal injuries

Hyenal tears

Reddening of hymen

Fourcheette tear

Dilated hemenal orifice

Loss of vaginal rugae

Reddening of Labia

Combination

No injuries
$01 \quad 01$

$--\quad 116$

$\begin{array}{ll}-- & 25\end{array}$

$\begin{array}{ll}-- & 31\end{array}$

$\begin{array}{ll}-- & 71\end{array}$

$\begin{array}{ll}-- & 61\end{array}$

$--\quad 16$

$--\quad 131$

14

Table 12. Type of hymenal tear

\begin{tabular}{ll}
\hline Type of tear & No: \\
\hline Fresh & 18 \\
Partially healed & 13 \\
Old healed & 85 \\
\hline
\end{tabular}

Table 13. Position of the hemenal tear

\begin{tabular}{ll}
\hline Place & No: \\
\hline 3 o clock & 47 \\
5 o clock & 27 \\
6 o clock & 83 \\
7 o clock & 14 \\
9 o clock & 56 \\
12 o clock & 08 \\
Combination & 93 \\
\hline
\end{tabular}

\section{DISCUSSION}

Sexual assaults by strangers have been reported as more violent and associated with more injuries than assaults by a person known to the victim $(5,6,7,8,9)$. This is in keeping with findings of this study as all the victims who had extra genital injuries been abused by an unknown person.

The victim's relationship to the assailant is consistent with earlier international studies and the majority of all assaults were committed by a person known to the victim $(10,11)$. 
Sexual assaults committed by an unknown person comprise $5.7 \%$ in this study population, which is somewhat lower when compared with studies from the United Kingdom and the United States $(5,12)$. Our results, establishing that only a minority of sexual assault victims have clinical evidence of fresh genital injuries, are supported by previous studies $(6,10$, 12). The genitoanal area has a remarkable healing capacity resulting in injuries disappearing quickly. One of the most important factors in the forensic examination is therefore the time lapse between the sexual assault and the examination. An examination after 72 hours will not show minor lacerations that might have been present earlier.

This study has some limitations and strengths that need to be mentioned. The study is retrospective, and the choice of variables was limited. Data collection was dependent on victim's report, and it is not clear how reliable it is to collect data within the context of a forensic examination shortly after a sexual assault because of peri traumatic dissociation. Some children did not recall or were unwilling to relate assault details. Data were collected from one hospital that in most cases probably would reduce generalizability, but as all sexual assault victim care in the Galle district are centralized to one unit, these are the circumstances that give strength to the study.

\section{CONCLUSIONS}

Children below 16 years of age from lower socio-economic group were more prone to sexual abuse. As they were below 16 years, this had amounted to statutory rape. The given "consent" and delayed presentation could be a reason for lack of injuries in both groups. A statistically significant difference was noted in relation to the age of the offenders. Young males have shown preference for female victims whereas older males have shown preference for younger boys. Low positive spermatozoa identification results could be due to delayed presentation and victims taking baths and changing clothes prior to referral. Steps needed to be taken to speed up the referral of victims with their original clothing in order to prevent loss of valuable evidence.

\section{REFERENCES}

1. Tharp AT, De Gue S, Valle LA, Brookmeyer KA, Massetti GMA, Systematic Qualitative Review of Risk and Protective Factors for Sexual Violence Perpetration. Trauma, violence and abuse. Published online on 27 December 2012. Available http://tva.sagepub.com/content/early/2012/ 12/27/1524838012470031.

2. Black, MC, Basile, KC, Breiding, MJ, Smith, SG, Walters ML, Merrick MT, 
Chen J, Stevens MR. (2011). The National Intimate Partner and Sexual Violence Survey (NISVS): 2010 Summary Report. Atlanta, GA: Centers for Disease Control and Prevention.

3. Möller AS, Bäckström T, Söndergaard HP, Helström L. Patterns of Injury and Reported Violence Depending on Relationship to Assailant in Female Swedish Sexual Assault Victims. Journal of Interpersonal Violence: 27: 3131-3148.

4. From a study by Professor H. de Silva. As quoted in second country report on the implementation of the convention on the rights of the child. Department of Probation and Childcare Services, Ministry of Social Services. 1998.

5. Jones JS, Wynn BN, Kroeze, B, Dunnuck C, Rossman L. (2004). Comparison of sexual assaults by strangers versus known assailants in a community-based population. American Journal of Emergency Medicine, 22, 454-459.

6. Palmer CM, McNulty AM, Déste C, Donovan B. (2004). Genital injuries in women reporting sexual assault. Sex Health, 1, 55-59.

7. Slaughter L, \& Brown CR. (1997). Patterns of genital injury in female sexual assault victims. American Journal of Obstetrics \& Gynecology, 176, 609-616.

8. Stermac LE, Du Mont JA, Kalemba, V. (1995). Comparison of sexual assaults by strangers and known assailants in an urban population of women. Canadian Medical Association Journal, 153, 1089-1094.

9. Sugar N F, Fine DN, Eckert LO. (2004). Physical injury after sexual assault: Findings of large case series. American Journal of Obstetrics \& Gynecology, 190, 71-76.

10. Grossin C, Sibille I, Lorin de la Grandmaison G, Banasr A, Brion F, Durigon M. (2003). Analysis of 418 cases of sexual assault. Forensic Science International, 131, 125-130.

11. Logan TK, Cole J, Capillo A. (2007). Differential characteristics of intimate partner: Acquaintance, and stranger rape survivors examined by a sexual assault nurse examiner. Journal of Interpersonal Violence, 22, 1066-1076.

12. Maguire W, Goodall E, Moore T. (2009). Injury in adult female sexual assault complainants and related factors. European Journal of Obstetrics \& Gynecology and Reproductive Biology, 42, 149-153.

\section{CORRESPONDENCE:}

Dr. R. H. A. I. Rathnaweera

Department of Forensic Medicine, Faculty of Medicine, Galle, Sri Lanka

E mail-ajithrathnaweera@gmail.com

Received: July 2017

Accepted: August 2017 